\title{
Empirical Research on Influence Factors of Service-oriented Small and Micro Enterprises
}

\author{
Zhengmao Chen \\ School of Management, China West Normal University, Nanchong Sichuan, 637002, China
}

Key words: Small and micro enterprises, Technical service type, Influence factor, Motivation, Source, Empirical analysis.

\begin{abstract}
In China, small and micro enterprises are a key constituent part of national economy. Their contributions to urban and rural economy and urbanization construction are great. Nowadays, the government also has issued a series of favorable policies such as encouraging immigrant workers to start business in their hometowns, reducing register threshold of small and micro enterprises and reducing or exempting taxes of small and micro enterprises. Thus, such enterprises will have better and larger development space in the future. However, in such severe economic market competition environment, small and micro enterprises are indeed faced with many survival problems in the development process. These problems bring about serious obstructions to their development. This paper tales service-oriented small and micro enterprises for example, discusses various internal and external influence factors in the growth process and carries out empirical research.
\end{abstract}

\section{Introduction}

Future development prospect of small and micro enterprises is promising in China, because of their meticulous classification and complete functions. Generally speaking, current small and micro enterprises are classified into three types: trade orientation, production orientation and service orientation. Service-oriented small and micro enterprises mainly introduced in this paper are directly oriented to customers with technical service and commodity service, including other small and micro enterprises in terminal market. Since service-oriented small and micro enterprises can be directly oriented to customers, they can better know customer's actual demand, and sense real-time market change immediately, so service-oriented small and micro enterprises are also of the enterprise type with the largest proportion in small and micro enterprise market.

\section{Development status of Chinese small and micro enterprises of IT technical service type}

After American subprime mortgage crisis in 2008, China also reduced GDP growth rate and showed the lack of strength in terms of traditional consumption, investment and export. Thus, numerous small and micro enterprises suffered huge influence in the aspect of operation and development. The survey data of national financial sector show only $12.5 \%$ of small and micro enterprises in China presented fast growth trend (higher than 30\%) in business volume after 5 years of subprime crisis, and the remaining small and micro enterprises were in the state of slow development, output and benefit lag. In addition, small and micro enterprises are faced with coercive extrusion of large enterprises in the market. Thus, social resources that small and micro enterprises can gain become fewer and fewer. Social resource allocation proportion loses balance seriously. It is found from a questionnaire survey with incomplete statistics that, after the subprime crisis, $45.78 \%$ of small and micro enterprises in China expressed that market resource demand was seriously insufficient, and production sale was difficult. 58.32\% of small and micro enterprises reflected market competition pressure was too heavy 
and enterprise survival was difficult. Besides, 20.21\% of small and micro enterprises said their orders are insufficient and they were faced with poor capital turnover.

In addition, in the report of Pudong Times, Shanghai local government also inspected 130 small and micro enterprises of IT technical service type at random and found their survival pressure was generally heavy and they had the problems of insufficient development strength and management lag. Among the enterprises investigated, 35.3\% of enterprises increased operation revenue, compared with the last year; $28.4 \%$ of enterprises leveled off; $40.2 \%$ of enterprises reduced operation revenue; $60.3 \%$ of enterprises were in the loss state. It is also found in another survey that, among the 130 small and micro enterprises, nearly $66.3 \%$ of enterprises were still in primary development stage, while only $13.4 \%$ of enterprises gradually became mature. This indicates that the development structure of local small and micro enterprises is quite unbalanced.

\section{Internal and external factors influencing growth and development of small and micro enterprises of technical service type}

Short life cycle and high death rate are widespread phenomena and problems that small and micro enterprises of technical service type are faced with. Since small and micro enterprises are directly oriented to customers, small and micro enterprises of technical service type are influenced by many factors in the development and growth process. Thus, small and micro enterprises of technical service type must solve their problems, pay attention to effective exertion of important functions, analyze influence factors of development from internal and external causes and investigate the sources.

\section{Analysis of internal cause}

Basic components of small and micro enterprises of technical service type include human, fund and material etc. Financial value they create is also a part of their life system and the important constituent unit of national economic development. In such case, small and micro enterprises of technical service type need to face a large number of customers and complete massive information and energy exchange. Thus, enterprises must achieve metabolism process form inside to outside, construct vitality organization suitable for their development, store energy for them and form resource polymer. To be specific, small and micro enterprises of technical service type must continuously seek excess earning and rent result in the growth process. According to Ricardo Rent Theory, external resources that small and micro enterprises of technical service type need to gather cannot be lower than earning rent of enterprises in competitive market. Such rent may come from now or exist in the future. As resource rent of enterprises, it is reflected in senior talents, organization knowledge, and technical patent of enterprises etc. For small and micro enterprises of technical service type, different sources have different functions and also bring different effects on enterprises. For example, resource viscosity of senior talents is weak. Once external premium phenomenon appears, staff turnover will happen. The resources of enterprise reputation and organization knowledge are continuously accumulated by small and micro enterprises of technical service type in the long-term development process. They represent evolutionary process of enterprises. Their path dependence is strong, and they belong to long-term "economic rent" of small and micro enterprises. Ricardo Rent Theory holds that it is hard to imitate some resources, and they own dynamic advantage. They are the key to sustainable development of small and micro enterprises of technical service type and also hard-won stable resources.

For small and micro enterprises of technical service type, internal cause for their growth totally depends on their control of resources, i.e. gain relatively stable and large-scale rend advantage for enterprises. Some rents are transient and can bring large-scale growth for enterprises. But some rend are long-term, and can consolidate economic foundation of small and micro enterprises, make them innovate continuously in uncertain market environment and create development space. Although market innovation brings sufficient external fund income for enterprises, it may be very unstable. 
Such resource is indeed an important source of driving growth of small and micro enterprises of technical service type.

\section{Analysis of external cause}

Small and micro enterprises of technical service type generally create open-type system. Their external environment is also essential base which decides enterprise survival and development. Since they need to face a large number of customers, small and micro enterprises must adapt ever-changing external environment, achieve active exchange with substance, information and energy in external environment, then realize orderly transformation and inject vigor for enterprise growth. Of course, external environment also has dynamic nature and uncertainty which are exogenous variables small and micro enterprises must be faced with. The generation of uncertain factors may come from subjective aspect or exist in objective environment. When small and micro enterprises are confronted with uncertain factors, information asymmetry and opportunism are presented. These result in uncertainty of decision action or enterprise transaction uncertainty. However, exogenous uncertainty of small and micro enterprises of technical service type is exactly the important foundation of their growth. Enterprises must adapt such uncertainty, effectively screen out external risks caused by such uncertainty and gain more stable and long-term benefit for enterprises. Therefore, uncertainty has been an important precondition for small and micro enterprises of technical service type to achieve growth. Single resource gathering contributes to reduction of such uncertainty. But on the whole, internal cause and other factors should be combined to create conditions for enterprise development and growth ${ }^{[1]}$.

\section{Empirical analysis for influence factors of small and micro enterprises of technical service type}

In China, influence factors of small and micro enterprises of technical service type mainly come from entrepreneurs' ability, financing ability, regional innovative network, technical innovation, policy and law environment, and financial ecological environment. Enterprises utilize these resources to pursue future development opportunity. Since each enterprise has different quantities of resources and their ability to utilize these resources is different, growth difference exists. For enterprises, entrepreneurs' ability, technical innovation and financing ability are endogenous influence factors. This paper analyzes the three influence factors and explores growth mechanism of small and micro enterprises of technical service type.

For a long time, China applies net profit growth rate and sales revenue growth rate to measure enterprise growth and development. Especially for small and micro enterprises of technical service type, these indicators are very important. But the shortcomings are also very obvious. Enterprise asset influence factor and industrial influence factor cannot be taken into account. Besides, the evaluation standards lack systematicness. Some enterprises apply financial indicators to reflect enterprise growth and development advantage, but in fact financial indicators cannot overall reflect human resource factor and technical factor etc. For development and performance growth of small and micro enterprises of technical service type, they should start from endogenous causes and utilize multiple indicators for empirical research.

\section{Study on development influence factors of small and micro enterprises of technical service type based on endogenous factors}

\section{Entrepreneurs' ability}

Entrepreneurs' ability will be introduced in economics theory, which was verified in the last century in Europe. Entrepreneurs' ability is mainly reflected in three aspects. The first aspect is spirit of innovation, because innovation is always the source power of economic development. Enterprises pursue and gain more excess profits for small and micro enterprises on the basis of breaking market equilibrium. Of course, entrepreneurs' spirit of innovation should be reflected to certain degree. Random innovation will bring heavy load for development of small and micro enterprises and finally 
result in collapse. The second aspect is scientific decision-making. Different from common employees, entrepreneurs are good at seizing market opportunity and able to formulate the optimal combination and allocation for enterprise resources and achieve profit maximization. The third aspect is risk undertaking. This is also an outstanding ability in entrepreneurs' abilities. Entrepreneurs own favorable risk decision-making ability which is especially important for small and micro enterprises of technical ssrvice type, because such enterprises are faced with higher ad stronger risks and competitions. Thus, based on the above three dimensions, entrepreneurs' ability should become an important topic of empirical research.

Technical innovation factor

Although small and micro enterprises of technical service type occupy an absolute important position in social and economic system and develop rapidly, their overall technical innovation ability is still weak and they cannot adapt increasingly diversified and homogeneous product market and fierce competition pattern. Thus, small and micro enterprises should improve innovation ability. For this, the academic circle proposes and designs specific measurement indicators for technical innovation of small and micro enterprises. Technical innovation ability is mainly reflected by three points: innovation input, innovation output and innovation base. Hence, empirical analysis of factors influencing development of small and micro enterprises of technical service type based on technical innovation should lay particular emphasis on the three dimensions.

Financing ability factor

Small and micro enterprises of technical service type need relatively small amount of capital in innovation process, and they mostly meet demand through self-raising, loan and private investment etc. When enterprise scale becomes larger and larger, financing channels become more and more and financing evaluation system becomes increasingly tedious. In general, financing ability of small and micro enterprises of technical service type should be evaluated from management, debt paying and profit on the basis of financial strength evaluation system including 9 three-level indicators. Generally, such enterprises should combine enterprise financing channels, financing potential and loan efficiency to analyze financing ability factors. Actual financing ability of small and micro enterprises of technical service type should be measured according to 11 standards such as loan-debt ratio and financial deficit ${ }^{[2]}$.

\section{Verification analysis based on endogenous influence factor}

Development analysis of small and micro enterprises of technical service type based on endogenous influence factor is combined with verification factor analysis model fitting index. Since it is easily influenced by the quantity of measurement items, 3-4 observation indicators are set at each order of factor so as to achieve better model fitting effect.

This paper applies AOMS software and achieves model fitting index calculation through 13 iterations. The fitting result gained is $\mathrm{P}=0.000<0.05$. the fitting value is within $0.8 \sim 1.0$. its upper limit is below 0.09 within $90 \%$ confidence interval. Model judgment standards and fitting index result show verification factor model in influence factors of small and micro enterprises of technical service type performs well in terms of fitting effect. This well explains the existence of enterprise development influence factors.

Empirical analysis of Model fitting index shows the path relationship between latent variable and corresponding observational variable is within rational range in the aspect of 3 influence factors of endogenous motivation of small and micro enterprises of technical service type. In particular, path relationship is prominent within $90 \%$ confidence interval. This also proves relative validity of model structure is good. In addition, according to different influence factors, higher correlation exists among factors. This to some extent explains small and micro enterprises of technical service type form complex relationship network through direct or indirect interaction of different influence factors. Enterprises should create more superior external environment, achieve all-round optimization and pay attention to mutual harmony among each influence factor while enhancing internal management. 
This is very beneficial to growth and development of small and micro enterprises of technical service type $^{[3]}$.

\section{Conclusion}

This paper explores and carries out empirical analysis of factors influencing growth and development of small and micro enterprises of technical service type. Main factors influencing enterprise development are confirmed after numerous factors such as enterprise feature and development rules are combined, such as endogenous motivation and external factor. All these are key problems which will profoundly influence the development of small and micro enterprises of technical service type. Deeper analysis should be conducted in future researches to help small and micro enterprises of technical service type in China to better cope with customer service and keep a foothold in market economization tide.

\section{Acknowledgments}

Subsidized by Basic application project of Technological Office of Sichuan (No.: 2013JY0093) and doctor scientific research project of China West Normal University (No.: 13E023).

\section{References}

[1] Lin Jixing, Study on strategic choice and operation plan of service-oriented small and micro IT enterprises - case study of W Company. Jiangxi Normal University, 2015.5-6.

[2] Cao Yu, Study on factors influencing business model innovation of small and micro enterprises of technical service type. Xidian University, 2014.29-39.

[3] Li Sensen, Research on factors influencing growth of small and micro enterprises of technical service type. Shandong University, 2014.96-101. 